\title{
MODELLING COMMODITY FUTURES PRICES: THE CASE OF CRUDE PALM OIL FUTURES
}

\author{
Khalil Ahmed $^{1 *}$, Zurina Shafii ${ }^{2}$, Amir Shaharuddin², and Siti Nurazira Mohd ${ }^{3}$ \\ ${ }^{1} I I U M$ Institute of Islamic Banking \& Finance (IIiBF), International Islamic University \\ Malaysia, P.O. Box 10, 50728 Kuala Lumpur, Malaysia \\ ${ }^{2}$ Faculty of Economics and Muamalat, Islamic Science University of Malaysia, \\ 71800 Nilai, Negeri Sembilan, Malaysia \\ ${ }^{3}$ Department of Economics and Agribusiness Management, \\ School of Economics, Finance and Banking, Universiti Utara Malaysia, \\ 06010 UUM Sintok, Kedah, Malaysia \\ *Corresponding author: khaleel8344814@yahoo.com
}

Published online: 20 March 2019

To cite this article: Ahmed, K., Shafii, Z., Shaharuddin, A., and Mohd, S.N. (2019). Modelling commodity futures prices: The case of crude palm oil futures. Asian Academy of Management Journal, 24(Supp. 1), 61-78. https://doi.org/10.21315/aamj2019.24.s1.5

To link to this article: https://doi.org/10.21315/aamj2019.24.s1.5

\begin{abstract}
The present paper seeks to fulfil the gap of knowledge in crude palm oil futures (FCPO) by employing unobserved component (UC) methodology. It may perhaps be the first study in Malaysian capital market to examine FCPO prices using UC model. The empirical results indicate that FCPO presents a permanent behaviour. The transitory component exhibits a higher degree of persistence with a periodicity of approximately one year. In addition, the model of the study has proven its ability to capture unobserved characteristics of FCPO's time series price and has shown a satisfactory performance for the sampled period in terms of fit. This study implicates that understanding the cyclical pattern, duration, and persistence provides important information that would help to create an appropriate strategy to manage risks, smooth and stabilise returns over the FCPO cycle. Such a strategy would ensure the stability and sustainability of the FCPO market.
\end{abstract}

Keywords: unobserved component model, permanent component, transitory component, standardised residuals, auxiliary residuals

(C) Asian Academy of Management and Penerbit Universiti Sains Malaysia, 2019. This work is licensed under the terms of the Creative Commons Attribution (CC BY) (http://creativecommons. org/licenses/by/4.0/). 


\section{INTRODUCTION}

In recent years, there has been a growing number of analyses on commodity futures prices. The frequent rise in the fluctuations of commodity futures have become a main concern for relevant parties, both at the academic and industrial levels. The prices of commodity futures have continuously fluctuated for years due to several reasons including monetary policy, supply and demand for the underlying assets, and macroeconomic variables. The highly volatile prices of commodity futures clearly reveal the uncertainty of the prices, which may adversely affect producers, investors, and hedgers in the capital market. Increased price variability of commodity futures has been documented in existing literature. While most studies are based on traditional models when analysing price fluctuations such as Generalised Autoregressive Conditional Heteroskedasticity (GARCH) and Autoregressive Conditional Heteroskedasticity (ARCH), the unobserved components (UC) model is rarely applied. To the researchers' knowledge, an application of this methodology to crude palm oil futures (FCPO) in Malaysia is novel and appears to be the first study to initiate the employment of this method based on a monthly observation. By employing UC, we can examine fluctuations in price levels, as well as decompose price series into their permanent and transitory components. The permanent component is called "trend", which represents the long-term development of a time series. On the other hand, the transitory component is termed "cycle", which embodies short-term movements. Estimates of these components provide a better understanding of the dynamics of the time series under study and provide intuitions as to which factors contribute to price fluctuations. Decomposing the economic series into permanent and transitory components largely contributes to the understanding of how these components relate to the underlying economic phenomena that shape their evolution (Fadiga $\&$ Misra, 2005). The permanent and transitory evolutions of commodity futures prices and their inter-relationships are important for investors and policy makers. For the former, it provides a better ability to cope with the price risk. For the latter, it enables an improved planning to limit interventions at the domestic level that may have adverse spillover effects (Alagidede, 2009).

\section{LITERATURE REVIEW}

A few studies have addressed the commodity futures' price time series behaviour by decomposing the time series into permanent and transitory components. Myers, Johnson, Helmar, and Baumes (2015) used the common trend-cycle decomposing analysis to study the long-run and short-run co-movement of corn oil and soybean commodity futures prices from January 1990 until August 2012. The results 
suggested that corn and soybean prices have a small transitory component. The correlation analysis between permanent and transitory components for each price series revealed that soybean and corn prices co-move strongly in the long-run and short-run. Although the sample period was long, the study did not discuss a specific method to test for potential structural breaks and outliers. However, this study uses a more updated sample period and employs a specific method to identify structural breaks and outliers. Similarly, Ozbek and Ozlale (2010) employed the trendcycle decomposition model to analyse oil prices' time series from January 1974 to February 2009. They allowed the parameters that govern the model to change over time to test whether shocks to the trend and cycle affect the price series of oil. They found that the shocks to trend were more persistent in recent time due to their supply-side driven and global economic activity. Fadiga and Misra (2005) employed UC model to examine the fluctuations in the prices of cotton, wool, rayon, and polyester in the fiber market based on yearly observations from 1960 until 2002. The results showed that the components were stochastic and determine the degree of uncertainty in the market. While the study confirmed the cyclical nature of the market, shocks belonging to the cycle component were transitory. However, shocks pertaining to the trend component were permanent and last longer. Furthermore, the study used quarterly data, which had a lower frequency. However, the present study utilises high-frequency data. In comparison to low-frequency data, high-frequency data offer a higher level of statistical significance (Rezitis \& Sassi, 2013). Sadorsky (2000) examined the variability of oil prices based on monthly frequency data from January 1970 to April 1996. Due to the fluctuations in oil prices after the mid-1980s, he found a stochastic trend that should be specified in the time series of oil prices.

\section{UNOBSERVED COMPONENTS MODEL OF FCPO}

Using UC model has a number of advantages over similar models. It allows direct economic interpretation of components in the model by dealing with multivariate series, some data irregularities like structural brakes and missing observations (Dudek \& Pachucki, 2011). In addition, flexibility of the state space models in terms of suitable formulation of particular components, possibility of work with nonstationary time-series, and the solution algorithm offered by the recursive procedure which is Kalman filter, makes them quite a powerful tool for economic analysis (Dudek \& Pachucki, 2011). Generally, the permanent component follows a random walk process, while the transitory component is assumed to follow a stationary autoregressive (AR) process (Koopman, Harvey, Doornik, \& Shephard, 2009). Following UC approach (Alagidede, 2009; Rezitis, Ntinou, \& Pachis, 2015), the permanent and transitory components are assumed to be a non-stationary stochastic process. This approach allows the examination of the long- and short-run dynamics 
of FCPO's prices while modeling the unobserved components associated with them. In the field of commodities, this approach seems to be the most plausible method to decompose time series into trend and cycle (Alagidede, 2009).

The FCPO's price series is additively decomposed into permanent and transitory components. Every component is modeled as a stochastic process that depends on normally and uncorrelated distributed disturbances. Stochastic formulation allows the trend and cycle to evolve over time (Junus, Ismail, \& Arsad, 2014), and it seems to be the most plausible way of decomposing the time series (Alagidede, 2009). Following Koopman et al. (2009) and Labys and Kouassi (1996), we sets up a model consisting of trend, cycle, and irregular components as follows:

$$
y_{t}=\mu_{t}+\psi_{t}+\varepsilon_{t} \quad t=1,2, \ldots, T, \quad \varepsilon_{t} \sim \operatorname{NID}\left(0, \sigma_{\varepsilon}^{2}\right)
$$

Where $\mu_{t}$ is the trend; $\psi_{t}$ is the cycle; $\varepsilon_{t}$ is the irregular white noise component; NID is normally and independently distributed; $y_{t}$ represents FCPO prices; and $\mu_{t}$ and $\psi_{t}$ represent the long- and short-term movements in the series, respectively. The trend component can be defined by the level and slope equations as follows:

$$
\begin{aligned}
& \mu_{t}=\mu_{t-1}+\beta_{t-1}+\eta_{t} \eta_{t} \sim \operatorname{NID}\left(0, \sigma_{\eta}^{2}\right) \\
& \beta_{t}=\beta_{t-1}+\zeta_{t} \zeta_{t} \sim N I D\left(0, \sigma_{\zeta}^{2}\right)
\end{aligned}
$$

Where, $\mu_{t}$ is the level of the trend and $\beta_{t}$ is the slope or drift of the trend. $\eta_{t}$ and $\zeta_{t}$ are white noise terms and assumed to be mutually independent of each other at all lags and leads. $\eta_{t}$ allows the level to move up and down whereas $\zeta_{t}$ allows the drift to change. Equations (1) and (2) jointly represent the local linear trend model. When $\sigma_{\zeta}^{2}$ is 0 , the trend follows a random walk with a constant drift. If $\sigma_{\eta}^{2}=0$, the trend is a smooth integrated random walk. In the case of $\sigma_{\eta}^{2}=\sigma_{\zeta}^{2}=0$, the trend is said to be linear deterministic. The level represents an actual value of the trend while the slope characterises the tendency to grow in the trend (Nakstad, 2006). The level and slope in the current study are assumed to be stochastic as well, which enables the trend to explain the most variations in the model (Nakstad, 2006).

Commodity futures prices are known for exhibiting price cycles as maintained by Labys and Kouassi (1996). Therefore, the cycle component (transitory) is included in the model as specified in Equation (1). The cycle component is considered as a function of time. Following Koopman et al. (2009), the cycle can be modeled as follows:

$$
\left[\begin{array}{l}
\psi_{t} \\
\psi_{t}^{*}
\end{array}\right]=\rho\left[\begin{array}{rr}
\cos \lambda_{c} & \sin \lambda_{c} \\
-\sin \lambda_{c} & \cos \lambda_{c}
\end{array}\right]\left[\begin{array}{c}
\psi_{t-1} \\
\psi_{t-1}^{*}
\end{array}\right]+\left[\begin{array}{c}
\omega_{t} \\
\omega_{t}^{*}
\end{array}\right]
$$


Where $\lambda_{c}$ is the cyclical frequency in the range of $0 \leq \lambda_{c} \leq \pi$ which is measured in radians, $\rho$ represents the damping factor for the amplitude of the cycle in the range of $0 \leq \rho \leq 1 . \omega_{t}$ and $\omega_{t}^{*}$ are white noise disturbance terms and are mutually uncorrelated with variance $\omega_{t} \sim N I D\left(0, \sigma_{\omega}^{2}\right)$ and $\omega_{t}^{*} \sim N I D\left(0, \sigma_{\omega^{*}}^{2}\right)$, respectively. The period of the cycle is determined by $2 \pi / \lambda_{c}$. If $0<\rho<1$, the forecast function is a damped sine or cosine wave (Harvey, 1989). If $\rho=1$, the forecast function is still a sine or cosine wave, but there is no damping movement present (Harvey, 1989). This case suggests that $\psi_{t}$ is non-stationary. Equation (3) can be written as a single equation as follows:

$$
\psi_{t}=\frac{\left(1-\rho \cos \lambda_{c} L\right) \omega_{t}+\left(\rho \sin \lambda_{c} L\right) \omega_{t}^{*}}{1-2 \rho \cos \lambda_{c} L+\rho^{2} L^{2}}
$$

Where $L$ is the lag operator. Equation (4) indicates that $\psi_{t}$ is an autoregressive moving average (ARMA) $(2,1)$ process. However, $\psi_{t}$ collapses to an AR (1) process if $\lambda_{c}=0$ or $\pi$. An appropriate UC model for FCPO price is a trend plus cycle model which starts with the formulation of Equations (1), (2), and (3) based on trend, cycle, and irregular components. These equations, in fact, represent the Basic Structural Model (BSM).

\section{ANALYSIS}

The data for this study are monthly frequency data spanning from January 1999 to December 2015. The selection of this specific period is mainly to avoid abnormal data issues that may have occurred in the pre-sampling period particularly, during the Asian financial crisis 1997-1998. The UC model for FCPO's price was estimated using the maximum likelihood coupled with the Kalman filter. Both were jointly used to estimate the model, variance parameters, loading matrices, frequency of the cycle, and the damping factor. Before conducting an empirical analysis, FCPO's price time series were transformed into the logarithmic form. The analysis was carried out using STAMP 8.2 (Structural Time Series Analyser, Modeller, and Predictor) econometric software of Koopman et al. (2009) to produce all estimations and test statistics. One of the attractive features of the UC model is that the data are not required to be stationary (Ardeni \& Wright, 1990). The parameters $\left(\sigma_{\varepsilon}^{2}, \sigma_{\eta}^{2}, \sigma_{\zeta}^{2}, \sigma_{\omega}^{2}, \lambda_{c}\right.$ and $\left.\rho\right)$ are estimated in the time domain using the maximum likelihood with Kalman filter. Following the UC approach, the first task was to specify the best fitted model followed by estimating the parameters, diagnostic checking of the residuals, and finally forecasting future values (Junus et al., 2014). A model with a stochastic level and stochastic slope was found to be 
the best fitted model. It is not surprising that such a model has the lowest value of Akaike Information Criterion (AIC) and a better estimation of fit $\mathrm{R}_{\mathrm{D}}^{2}$. This model is reduced to a local level random walk with a drift because $\sigma_{\zeta}^{2}$ is equal to zero.

Table 1 presents the maximum likelihood estimation for the variances of disturbances. The values for level and cycle are (0.006) and (0.00001), respectively. The value for slope and irregular are zero, which simply implies that they are deterministic. The value of the slop indicates that the slope changes very slowly over time. One of the essential points regarding any model is to ensure that the variance of irregular is as small as possible (Nakstad, 2006). The value of the irregular component corresponding to zero suggests that all variations in the model are accounted for by the movements in the trend and cycle and that there is no unexplained movement. However, the trend explains most of the variation in the model since the q-ratio corresponds to one. Besides, the magnitude of the amplitude is very small (0.019) which implies that the permanent component accounts for most of the variability in FCPO prices. Thus, movements in FCPO prices are primarily driven by the permanent component. This result is consistent with the report by Reinhart and Wickham (1994) who maintained that the volatility in commodity prices is mostly due to the permanent component and is not a product of transitory deviation from the trend.

Table 1

Summary of the statistics of variance disturbances

\begin{tabular}{lcc}
\hline Variances of disturbances & Value & (q-ratio) \\
\hline Level $\sigma_{\eta}^{2}$ & 0.0060 & $(1.000)$ \\
Slope $\sigma_{\zeta}^{2}$ & 0.0000 & $(0.000)$ \\
Cycle $\omega_{t}$ & $1.5438 \times 10^{-5}$ & $(0.0026)$ \\
Irregular $\sigma_{\varepsilon}^{2}$ & 0.0000 & $(0.000)$ \\
\hline
\end{tabular}

Figure 1 shows the graph of the trend (permanent) component. The level varies substantially, which indicates that the trend becomes more stochastic. The trend is characterised by interventions, which account for structural breaks that probably arise because of two reasons. First, the macro policy rules imposed by the Malaysian government on windfall profit levy on the underlying asset (CPO) in October 2008. Second, the policy announcement such as the case in April 2009 when Bursa Malaysia Derivative Berhad (BMDB) announced the establishment of a strategic partnership with Chicago Mercantile Exchange (CME). According to Reinhart and Wickham (1994), policy changes and announcements can cause significant swings in prices. As for the cycle (transitory) component, although 
the value of disturbance is close to zero, it is still positive. This suggests that the cycle is stochastic. The cycle component is driven by a variety of factors including policy changes and supply and demand. The occurrence of these factors has a large degree of randomness, which makes the parameters of the cycle stochastic (Mu \& Ye, 2015).

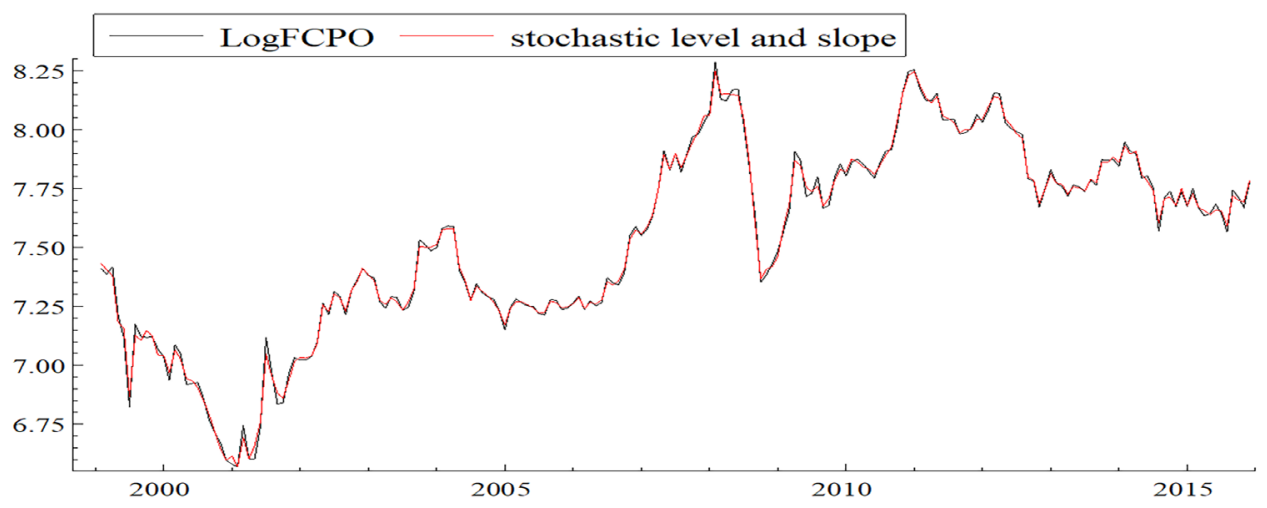

Figure 1. Logarithmic trend of FCPO

Table 2 presents short-run fluctuations of the transitory component in FCPO's prices. The period of the cycle was 11.8 months, which was roughly 12 months or 1 year. This period corresponds quite well with the standard business cycle period for commodities as maintained by Labys and Kouassi (1996), and Cashin and McDermott (2002). Labys and Kouassi (1996) argued that the cycle component in agricultural commodity is often production driven with a period of 12 months. Cashin and McDermott (2002) also maintained that the cycle in commodity is a 12 -month period due to the annual production process in agricultural commodities. The period of the cycle implies that it takes one year for a shock on FCPO to dissipate. The cycle is highly persistent since the damping factor is 0.98 . The amplitude is 0.019 indicating that the amplitude of the cycle as a percent of the trend is estimated at $1.9 \%$. This small magnitude in amplitude suggests that the permanent component explains most of the variability in FCPO prices. The variation of the cycle in the earlier sample is smaller compared to the cycle variation from 2007 onwards. Figure 2 depicts the cycle component as it is very small. It rarely deviates from the trend by less than $0.03 \%$. The amplitude was very low at the beginning of the sample and started to increase from 2007 and reached its highest in 2008 and 2009. Such an increase may be due to the uncertainty associated with policy changes, oil prices, and early signs of credit crunch that began in 2007 . The highest amplitude was estimated during October 2008 as a result imposing a windfall profit levy by the Malaysian government on the underlying asset (CPO), 
which indirectly affected FCPO. Harvey and Koopman (1992) maintained that a sharp decrease or increase in prices can be easily attributed to indirect tax changes or oil prices. This result provides important information for policy makers as the amplitude and period of FCPO's price cycle are key elements for designing policies in order to control shocks. Moreover, this provides an insight for investors to take into account the risk inherent in cyclical variations and also to make informed decisions about trading FCPO commodity.

Table 2

Cycle parameters

\begin{tabular}{lc|ll}
\hline Period $\left(2 \pi / \lambda_{c}\right)$ & 11.77 & Period in years $\left(2 \pi / \lambda_{c}\right)$ & 0.98 \\
Frequency $\left(\lambda_{c}\right)$ & 0.5337 & Damping factor $(\rho)$ & 0.98 \\
Amplitude & 0.019 & & \\
\hline
\end{tabular}

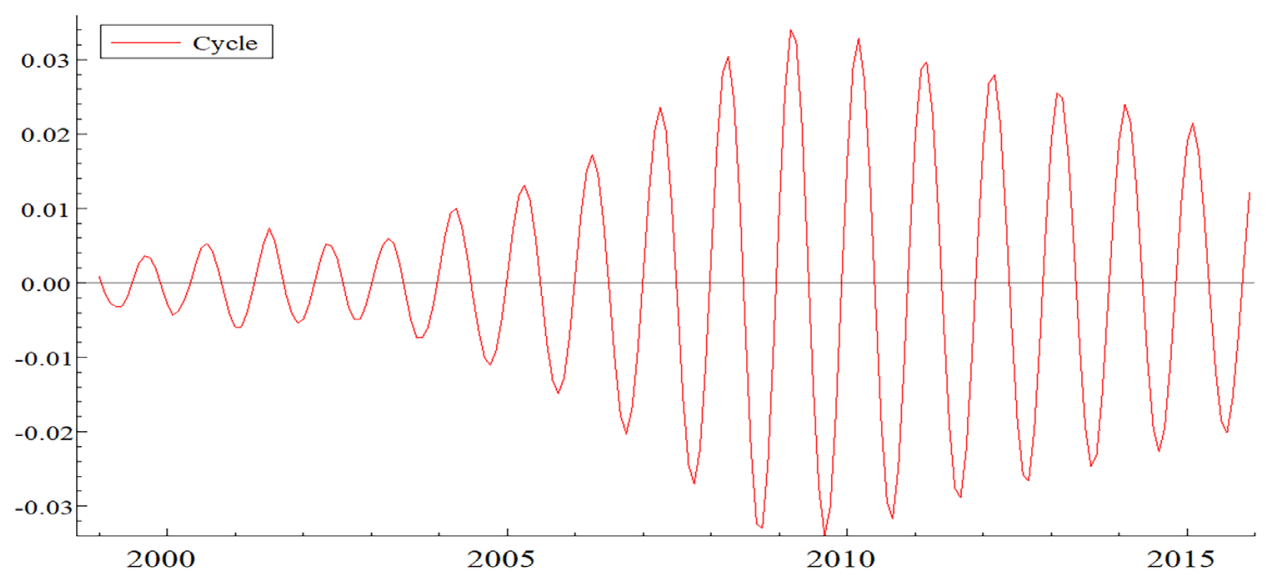

Figure 2. Cycle component

A damping factor $(\rho)$ of 0.98 shows that the cycle component is highly persistent. This finding is in line with the majority of empirical literature which suggested that the transitory component in various commodity prices exhibits a high degree of persistence (Alagidede, 2009; Rezitis \& Sassi, 2013). Once the transitory component deviates from the trend component, it then needs a long time to return to its permanent component. Therefore, the duration of cycle and persistence implies that it may take a long time for a temporary shock to fade away entirely without a lasting impact. 


\section{Diagnostic Tests for Standardised Residuals}

Diagnostic tests were carried out to check the validity of the UC model used in the current study. There are two diagnostic tests for residuals, namely standardised and auxiliary. The former was employed to check for normality, heteroscedasticity, and serial correlation, while the latter was used to identify outliers and structural breaks.

Commandeur and Koopman (2007) argued that the residuals are the standardised one-step-prediction error. The standardised residuals tests include testing the model residuals to confirm that the residuals have satisfied common assumptions. The results from Table 3 indicate that the model passed all the diagnostic tests. Normality follows an asymptotically $\chi^{2}$ distribution with two degrees of freedom. The value of normality 3.87 while the $5 \%$ critical value of $\chi_{2}^{2}$ is 5.99 . The residuals in Figure 3 are normally distributed. This finding is confirmed by the Q-Q plot in Figure 4 . The quantiles lie very closely to the straight line. Thus, the residuals are independent and normally distributed. H (65) is the test for heteroscedasticity for an $F$ distribution with $(65,65)$ degrees of freedom. The critical value of $F_{(65,65)}$ is 1.66 and since $1 / \mathrm{H}(65)<F_{(65,65 ; 0.025)}$, the null hypothesis of equal variance is not rejected, and there is no significant heteroscedasticity (see Figure 5).

Table 3

Standardised residuals diagnostics of the FCPO model

\begin{tabular}{ll|lc}
\hline Normality & 3.8783 & r (1) & 0.086997 \\
H (65) & 0.71080 & Q (q, q-p) & 20.671 \\
DW & 1.7955 & & \\
\hline
\end{tabular}

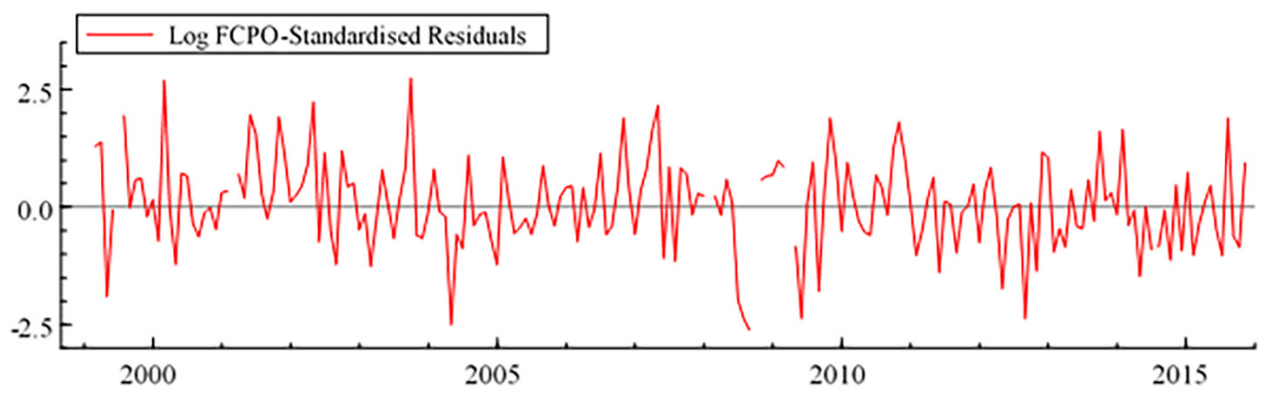

Figure 3. Standardised residuals 


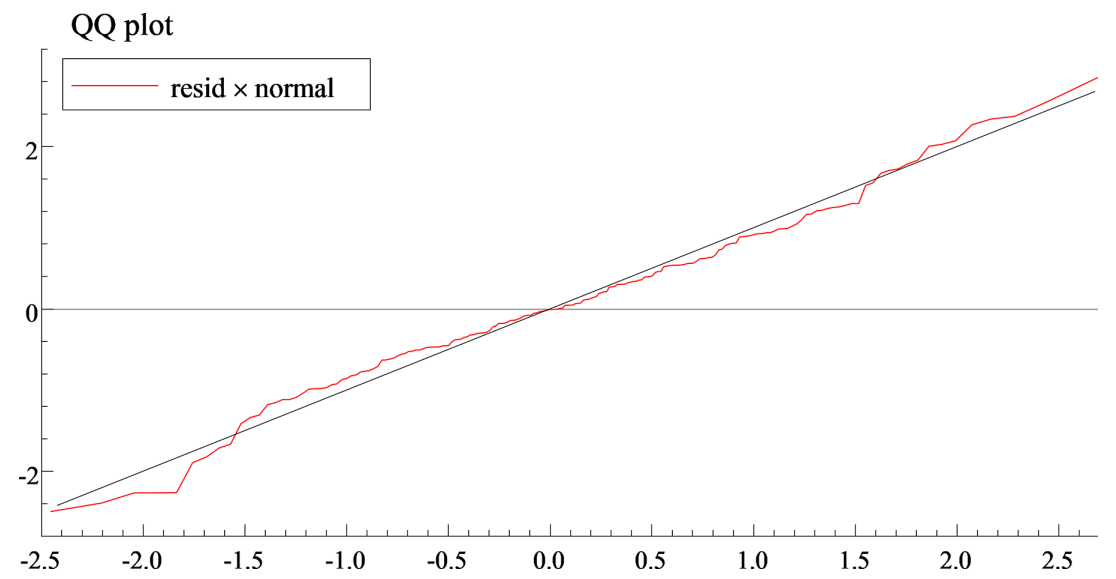

Figure 4. QQ plot of standardised residuals

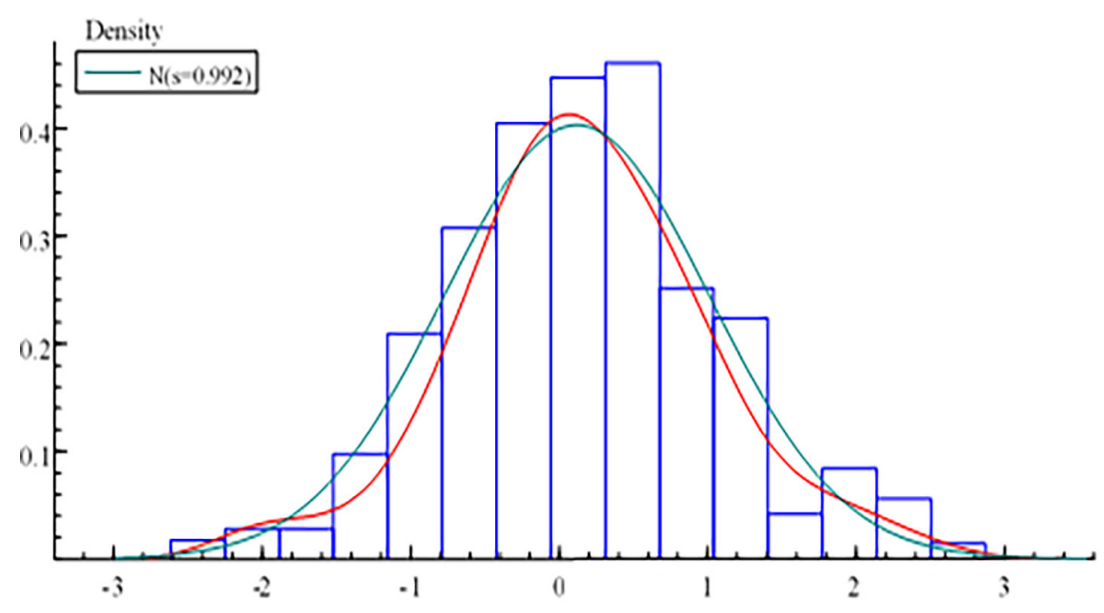

Figure 5. Histogram of standardised residuals

DW is the classical Durbin-Watson test statistic for the first order serial correlation, distributed approximately as $\mathrm{N}(2,4 / \mathrm{T})$. The observed DW value for the present study is 1.7955 , which is very close to 2 and there is no significant autocorrelation in the residuals as shown in Figure 6. Supporting this finding, Figure 7 shows that the spectrum is a reasonably flat horizontal line. This suggests that the model is white noise and the residuals are not autocorrelated. Serial correlation coefficient at the first lag $\mathrm{r}(1)$ is approximately distributed as $\mathrm{N}(0,1 / \mathrm{T})$. The value of $\mathrm{r}(1)$ is (0.086) suggesting that the tendency for FCPO's prices to increase in one period will be followed by a further increase in the next period since the serial correlation is positive. 


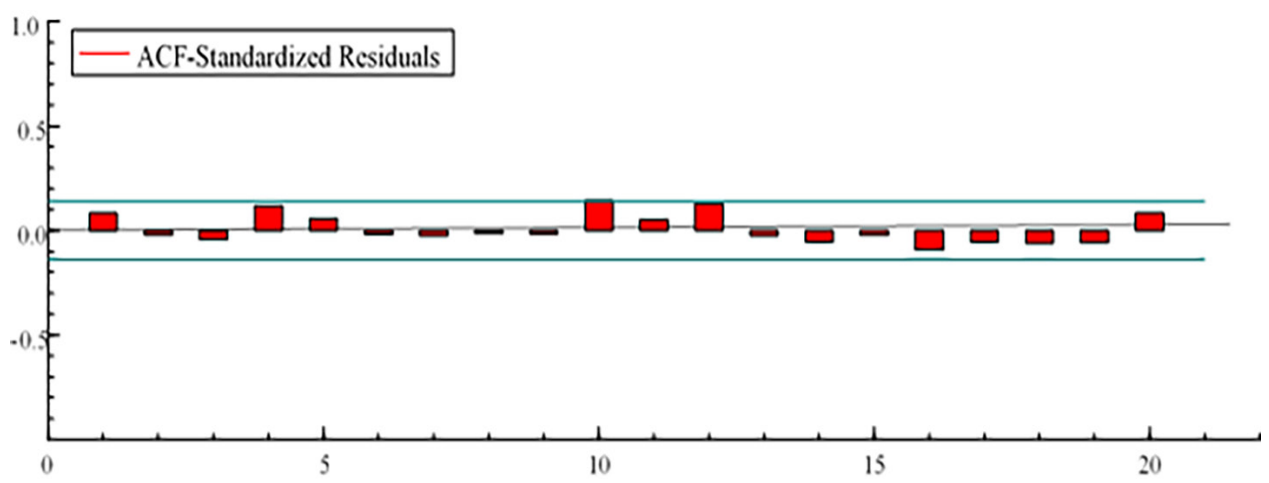

Figure 6. The correlogram of standardised residuals

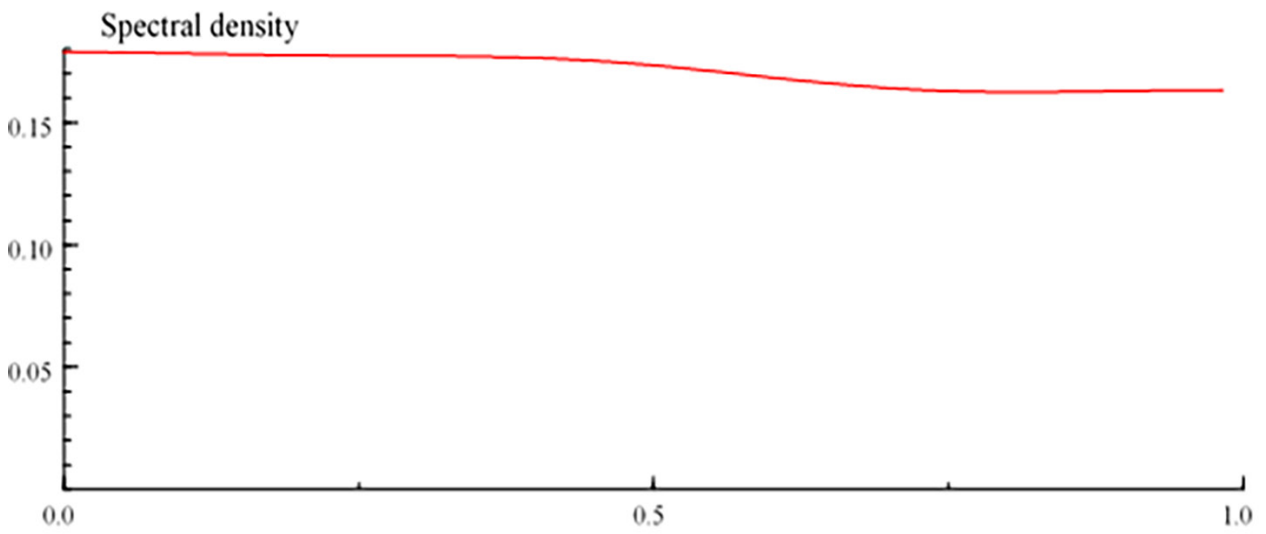

Figure 7. Spectral density of standardised residuals

$\mathrm{Q}$ (q, q-p) is the Ljung-Box Q-statistic test for serial correlations in the residuals based on the first 24 sample autocorrelations. The Ljung-Box is tested against $\chi^{2}$ distribution with 21 degrees of freedom. The value $Q$ test is 20.671 and the critical value of $\chi_{21}^{2}$ at $5 \%$ level of significance is 32.67 . Since Q $(24,21)$ is smaller than the critical value, there is no evidence to assume that the residuals are serially correlated as clearly revealed by Figure 8 . 


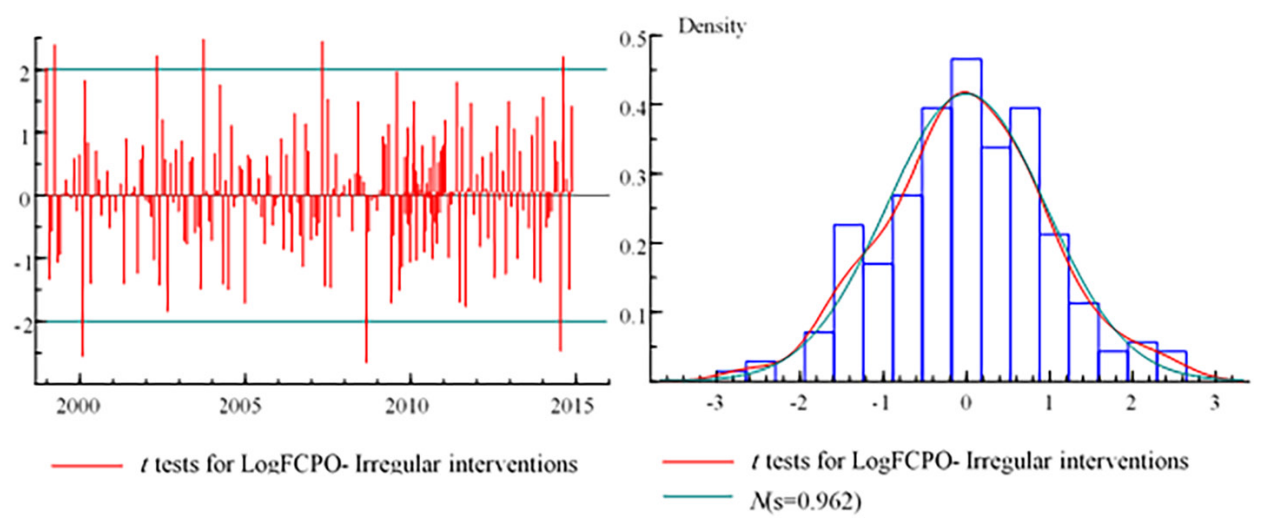

Figure 8. Auxiliary residuals plots and histogram: Irregular

\section{Diagnostic Tests for Auxiliary Residuals and Interventions}

The results from Table 4 suggested that the normality values for auxiliary residuals (irregular and level components) were well-behaved. The $p$-value for the two components were greater than 0.05 .

Table 4

Diagnostic test for auxiliary residuals: Irregular and level

\begin{tabular}{llll}
\hline FCPO & Skewness $[p$-value $]$ & Kurtosis $[p$-value $]$ & Bowman-Shenton $[p$-value $]$ \\
\hline Irregular & $0.00080635[0.9773]$ & $0.016369[0.8982]$ & $0.017175[0.9914]$ \\
Level & $0.010019[0.9203]$ & $1.7778[0.1824]$ & $1.7878[0.4091]$ \\
\hline
\end{tabular}

Figures 8 and 9 are graph plots and histograms for the $t$-value corresponding to auxiliary residuals for irregular and level components. Rezitis and Sassi (2013) argued that if the $t$-value does not exceed 3 in absolute value, the most extreme interventions have been included in the model. As illustrated in Figures 9 and 10, all intervention variables were included in the model. Although we can see that the possible outliers in Figure 9 exceeded the 95\% confidence limit by 8 points, they were still less than 10-time points. According to Commandeur and Koopman (2007), if the time points exceeded $n / 20$, then we can say that an outlier is not included in the model. Figure 9 indicates that 8-time points exceeded the $95 \%$ confidence limit corresponding to a 2 -tailed $t$-test. This was less than $n / 20=204 / 20=10.2$-time points expected to exceed the confidence limit. Level interventions were also included in the model since eight-time points exceeded the confidence limit, while the expected time points were 10 . We can say that all level interventions had been included in the model. 

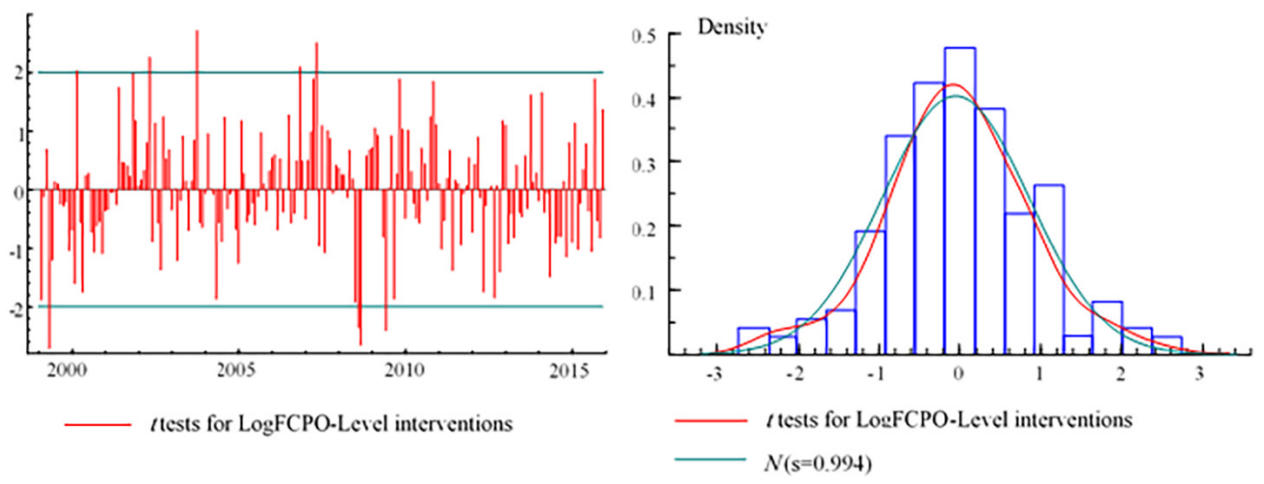

Figure 9. Auxiliary residuals plots and histogram: Level

\section{Intervention Analysis}

Interventions for irregular and level components are required for the UC model of the study to maintain the normality of the residuals. These interventions provide important information on sudden movements which took place at certain dates during the estimated sample period. Including these interventions in the model improves the consistency and efficiency of the estimates. A structural break or level shift indicates a permanent change in the level of the series, while an outlier represents temporary changes in the time series (Rezitis et al., 2015). Structural Time Series Analyser, Modeller, and Predictor (STAMP) software can detect structural breaks and outliers based on auxiliary residuals which are smoothed estimates of disturbances (Harvey \& Koopman, 1992). STAMP detected six interventions, four outliers and two-level shifts as reported in Table 5.

Table 5

Regression effects in final state at time 2015(12)

\begin{tabular}{lcrl}
\hline Interventions & Coefficient & $t$-value & $p$-value \\
\hline Level break 2008(10) & -0.27048 & -3.75251 & 0.00023 \\
Level break 2009(4) & 0.23661 & 3.28184 & 0.00122 \\
Outlier 1999(7) & -0.31730 & -6.26288 & 0.00000 \\
Outlier 2001(3) & 0.15979 & 3.15386 & 0.00186 \\
Outlier 2008(2) & 0.18380 & 3.62789 & 0.00036 \\
Outlier 2014(8) & -0.16209 & -3.19934 & 0.00161 \\
\hline
\end{tabular}

The empirical results show that all interventions were statistically significant at $5 \%$. There were two structural breaks: one has a negative effect while the other has a positive effect. Similarly, half of the outliers had a negative effect whereas 


\section{Khalil Ahmed et al.}

the remaining two had a positive effect. The structural breaks seemed to capture the trend very well and were driven by macro-policy factors (imposing a windfall profit levy and establishing strategic partnership between BMDB and CME.

\section{Goodness-of-fit}

Goodness-of-fit is a statistical test that shows the accuracy of the model in which the model approximates the observed data (Verbeek, 2008). It is based on the onestep-ahead prediction error.

Table 6 shows information related to goodness-of-fit. The ordinary $R^{2}$ exceeds the critical value of 0.70 applied in unobserved components studies (Koopman et al., 2009). The coefficient of determination, $R_{d}^{2}$, given a better fit and predictive performance since $0<R_{d}^{2} \leq 1$. Moreover, the standard error value is minimal. It is below the 0.30 acceptable level applied in unobserved components studies (Koopman et al., 2009). The prediction error variance (PEV) shows a very low value which indicates that the model is reliable (Nakstad, 2006) and informative (Liao \& Chang, 2006).

Table 6

Goodness-of-fit statistics

\begin{tabular}{ll|ll}
\hline Log L & 511.055 & $R^{2}$ & 0.97 \\
$R_{d}^{2}$ & 0.38 & Std. error & 0.070 \\
PEV & 0.0049 & PEMD & 0.0037 \\
AIC & -5.223 & BIC & -5.077 \\
\hline
\end{tabular}

Note $: \mathrm{PEV}=$ prediction error variance; $\mathrm{PEMD}=$ prediction error mean deviation; $\mathrm{AIC}=$ Akaike information criterion; $\mathrm{BIC}=$ Bayesian information criterion

\section{Prediction Test}

Prediction accuracy is a critical element for model adequacy. Assessing the adequacy of a model can be achieved by examining the performance of the model outside of the sampled period. The post-sample predictive test is employed to investigate the forecasting accuracy of the FCPO's model. The sum of squares of the onestep-ahead prediction error measures the accuracy of forecasting (Koopman et al., 2009). The null hypothesis assumes that the predicted value from the fitted model is the same as the actual value. STAMP retains the last 24 observations, 2014 (1) to 2015 (12), as a basis for the post-sample prediction test. 
From Table 7, it is safe to say that the post-sample performance of the model is accurate. This suggests that the estimated model is appropriate and its forecasting performance is reasonably accurate.

The failure test resulted in 22.3882 when tested against the $5 \%$ of $\chi_{23}^{2}$ critical value of 35.17 and there is no evidence to reject the null hypothesis and the prediction performance of the model is accurate. Root mean square error (RMSE) and cumulative sum (CUSUM) confirm the stability and accuracy of the model's prediction (see Figure 10).

Table 7

Post-sample prediction test

\begin{tabular}{lcc}
\hline Test & Value & $p$-value \\
\hline Failure $\chi_{23}^{2}$ test & 22.388 & 0.496 \\
CUSUM $(23) t$-test & -0.232 & 1.182 \\
\hline
\end{tabular}
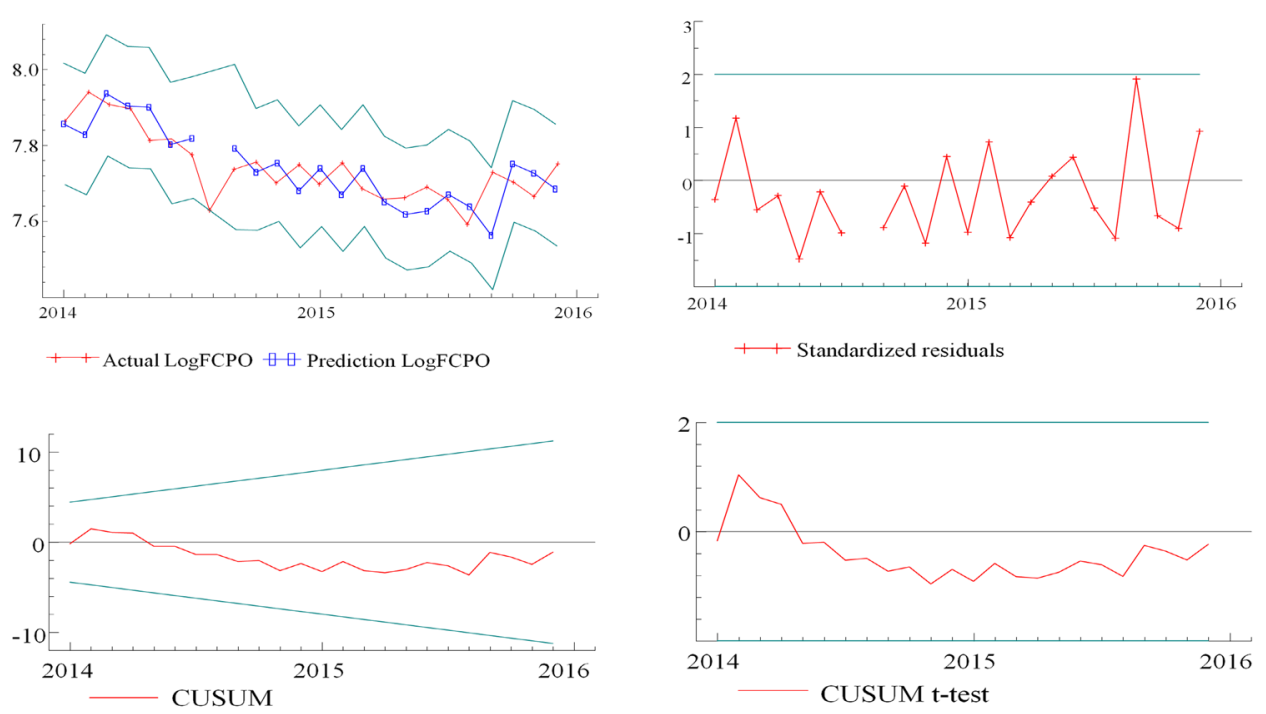

Figure 10. Prediction test results for the log of FCPO prices

\section{DISCUSSION}

It is shown that FCPO prices experienced significant swings during the sampled period. The UC results suggest that the source of volatility and variations in FCPO prices is primarily due to the permanent component. The fluctuations in 
FCPO prices would suggest that the permanent component is characterised by structural breaks which took place between October 2008 and April 2009. As the permanent component is characterised by structural breaks, it provides an evidence that holds a vital key in formulating policies ensuring the smoothing and stabilising of such fluctuations. Improper reading of structural breaks in a trend may generate unnecessary policies that could destabilise the FCPO prices. The variance of the transitory (cycle) component is very small, indicating that the transitory component is stochastic and less volatile. In addition, the cycle shows a high degree of persistence implying that it reverts to its permanent component slowly, but without a lasting impact. Generally, the duration of cyclical activity in agricultural commodity prices is production driven and estimated to be 12 months, which is confirmed by the cycle in FCPO prices. The duration of the cycle is roughly 12 months with a 0.019 amplitude. Although the cycle has a periodic property, its character shows irregular movements. In the long-run, the cycle movement fades away, and the price converges to its permanent component.

\section{CONCLUSION}

The present study has analysed the prices of FCPO from January 1999 to December 2015 using UC model. The price series were decomposed into their permanent and transitory components. The findings showed that FCPO presents a permanent behaviour and the transitory component exhibits a higher degree of persistence with a periodicity of approximately one year. Furthermore, the model of the study has proven its ability to capture unobserved characteristics of FCPO's time series price and has shown a satisfactory performance for the sampled period in terms of fit. The implications of the study imply that understanding the cyclical pattern, duration, and persistence provides important information that would help to create an appropriate strategy to manage risks, smooth and stabilise returns over the FCPO cycle. Such a strategy would ensure the stability and sustainability of the FCPO market. Hedgers and investors in the market may also take advantage of this information to hedge the risk inherent in cyclical fluctuations and to dampen the magnitude of the cycle in order to make informed decisions about investment opportunities. The time to hedge or invest in the FCPO market should be planned to take advantage of the cyclical upwards to improve profitability. 


\section{REFERENCES}

Alagidede, P. (2009). Trends, cycles and seasonal components in primary commodities: State space modeling and the Kalman filter. Ashesi Economics Lectures Series Journal, 1(1), 1-6.

Ardeni, P., \& Wright, B. (1990). The long-term behavior of commodity prices. Policy, Research and External Affairs (working paper), 358: 1-54

Cashin, P., \& McDermott, C. J. (2002). The long-run behavior of commodity prices: Small trends and big variability. International Monetary Fund. IMF Staff Papers, 49(2), $1-28$.

Commandeur, J.J.F., \& Koopman, S. (2007). An introduction to state space time series analysis. United Kingdom: Oxford University Press Inc.

Dudek, S., \& Pachucki, D. (2011, October). Unobserved component model with observed cycle use of BTS data for short-term forecasting of industrial production. Paper presented at the 30th CIRET Conference, Poland.

Fadiga, M., \& Misra, S. (2005). Common trends, common cycles, and price relationships in the international fiber market: Evidence from a seemingly unrelate structural time series. Paper presented at the Southern Agricultural Economics Association Annual Meetings, Arkansas.

Harvey, A.C. (1989). Forecasting, structural time series models and the Kalman filter. Cambridge, UK: Cambridge University Press.

Harvey, A.C., \& Koopman, S.J. (1992). Diagnostic checking of unobserved components time series models. Journal of Business and Economic Statistics, 10, 377-389. https://doi.org/10.1080/07350015.1992.10509913

Junus, N., Ismail, M., \& Arsad, Z. (2014, August). Behavior of road accidents: Structural time series approach. Paper presented at the International Conference on Quantitative Sciences and Its Applications, Kedah, Malaysia. https://doi.org/ $10.1063 / 1.4903671$

Koopman, S.J., Harvey, A.C., Doornik J.A., \& Shephard, N. (2009). Stamp 8.2: Structural time series analyzer, modeler and predictor. London: Timberlake Consultants.

Labys, W.C., \& Kouassi, E. (1996). Structural time series modeling of commodity price cycles (Research Paper No. 9602). West Virginia: Regional Research Institute, West Virginia University

Liao, S.-L., \& Chang, J.-C. (2006). Economic determinants of default risks and their impacts on the pricing of credit derivatives. PhD dissertation, National Chengchi University, Taiwan. $\mathrm{s}$

Mu, X., \& Ye, H. (2015). Small trends and big cycles in crude oil prices. The Energy Journal, 36(1), 49-71. https://doi.org/10.5547/01956574.36.1.3

Myers, R., Johnson, S., Helmar, M., \& Baumes, H. (2015). Long-run and short-run comovements between oil and agricultural futures prices. Retrieved from https:// pdfs.semanticscholar.org/402b/316356984b102e3f89413958611315e48953.pdf

Nakstad, Y. (2006). Structural time series models: Theory and application. Masters dissertation, University of Oslo, Norway. 
Ozbek, L., \& Ozlale, U. (2010). Analysis of real oil prices via trend-cycle decomposition. Energy Policy, 38(7), 3676-3683. https://doi.org/10.1016/j.enpol.2010.02.045

Reinhart, C., \& Wickham, P. (1994). Commodity prices: Cyclical weakness or secular decline? International Monetary Fund Paper, 41(2), 175-213. https://doi.org/ $10.2307 / 3867506$

Rezitis, A., Ntinou, A.G., \& Pachis, D.N. (2015). Investigating the international prices of wheat and rice. Agricultural and Food Economics, 3(1), 1-17.

Rezitis, A.N., \& Sassi, M. (2013). Commodity food prices: Review and empirics. Economics Research International, 2013, 1-15. https://doi.org/10.1155/2013/694507

Sadorsky, P. (2000). The empirical relationship between energy futures prices and exchange rates. Energy Economics, 22(2), 253-266. https://doi.org/10.1016/ S0140-9883(99)00027-4

Verbeek, M. (2008). A guide to modern econometrics. United Kingdom: John Wiley \& Sons Ltd. 